\title{
A comparative study of efficacy of misoprostol with methyl ergometrine and carboprost in active management of third stage of labour
}

\author{
Pradnya A. Supe*, Shailesh J. Kore, Y. S. Nandanwar
}

Department of Obstetrics and Gynaecology, L. T. M. M. C and L. T. M. G. H, Mumbai, Maharashtra, India

Received: 04 March 2016

Revised: 01 April 2016

Accepted: 07 April 2016

\section{*Correspondence:}

Dr. Pradnya A. Supe,

E-mail: pradssupe @gmail.com

Copyright: () the author(s), publisher and licensee Medip Academy. This is an open-access article distributed under the terms of the Creative Commons Attribution Non-Commercial License, which permits unrestricted non-commercial use, distribution, and reproduction in any medium, provided the original work is properly cited.

\begin{abstract}
Background: To assess the efficacy and safety of Misoprostol 800ug per rectally in active management of third stage of labour.

Methods: In this prospective study, a total of 200 pregnant women who delivered after 34 weeks of gestation at a tertiary teaching institute were included. The women were divided in to 4 groups by using randomization depending on the drug given at birth of anterior shoulder. Group A were given 800ug of Misoprostol per rectally, Group B were given $0.2 \mathrm{mg}$ of methyl ergometrine, Group C were given 125ug of Carboprost and Group D was the control group. The duration of third stage of labor and the blood loss was calculated and the results of all four groups were compared.

Results: Out of 200 antenatal women, the average duration of third stage of labor was shortest in the misoprostol group (8.88 minutes).The reduction in blood loss was significant with misoprostol as compared to ergometrine $(\mathrm{p}=0.016)$ and carboprost (0.009). The difference in pre and post-delivery hemoglobin was also significantly significant with misoprostol as compared to methyl ergometrine (0.048), carboprost (0.0001) and control (0.006).

Conclusions: Misoprostol 800ug per rectally is an effective alternative in the active management of third stage of labor as compared to methyl ergometrine and carboprost.
\end{abstract}

Keywords: Third stage of labor, Misoprostol, Postpartum Hemorrhage

\section{INTRODUCTION}

Postpartum hemorrhage is a single largest and leading cause of maternal morbidity and mortality, not only in developing countries, but also in developed countries. Worldwide, postpartum hemorrhage is responsible for almost 125,000 maternal deaths per year and it is associated with morbidity in 20 million women per year. Common causes for postpartum hemorrhage (PPH) include failure of the uterus to contract adequately after birth leading to atonic postpartum hemorrhage, tears of the genital tract leading to traumatic PPH and bleeding due to retention of placental tissue. Atonic PPH is the most common cause of $\mathrm{PPH}$ and the leading cause of maternal death.
One intervention that has been promoted as an effective intervention in preventing atonic PPH is the active management of third stage of labour. This intervention has been described in Cochrane review as administration of prophylactic uterotonic after delivery of the baby, early cord clamping and cutting and controlled cord traction. Expectant management involves waiting for signs of separation of placenta and allowing it to deliver spontaneously, or aided by gravity or nipple stimulation. ${ }^{1}$

Drugs conventionally used for prophylaxis against postpartum haemorrhage include oxytocin, methyl ergometrine and 15 methyl PGF2 $\alpha$. Prophylactic use of oxytocic agents after delivery of the infant has been shown to reduce the incidence of postpartum haemorrhage by $40 \%$.The use of these uterotonic agents 
in the management of third stage of labour reduces the amount of bleeding and need for transfusion. But it is associated with side effects ranging from nausea, vomiting, and increased blood pressure to postpartum convulsion, intracerebral haemorrhage, myocardial infarction, cardiac arrest and pulmonary oedema etc.

Ergometrine was the first of the injectable oxytocic's used in postpartum haemorrhage and has been in use for past 70 years. It produces prolonged uterine contractions involving the upper and lower uterine segments with a duration of 60-120 minutes. It is one of the most commonly used drugs but has side effects like nausea, vomiting and because of its prolonged effect can cause increase in uterine entrapment of the separated placenta. Its advantages are its easy availability, lesser cost and ease of storage.

15 methyl PGF $2 \alpha$ or Carboprost is the 15-methyl analogue of the parent compound PGF $2 \alpha$.Its advantage is that at a comparable dose, it has a strong uterotonic effect as compared to other oxytocic's like methyl ergometrine and misoprostol and less of the undesirable smooth muscle stimulation effects including nausea, vomiting, diarrhoea, vasospasm and bronchospasm. The duration of action is up to 6 hours and though, on the basis of cost and side effects, it is not recommended for routine prophylaxis it is a very useful agent when a prolonged oxytocic effect is required.

Misoprostol, a PGE1 analogue marketed for peptic ulcer disease has proven to have uterotonic effects when administered orally, rectally and vaginally. It has a shelf life of several years and hence does not require specific conditions for storage as it is stable at extremes of temperature. It is the cheapest oxytocic available and the only one which can be given by a non-parenteral use .It does not raise blood pressure in doses up to 800 micrograms and can be an effective alternative to methyl ergometrine for third stage of labour. It has a low side effect profile with shivering, mild pyrexia and diarrhoea being the main associations. It is slightly less effective than injectable oxytocic's but it is a drug of enormous potential for use in the developing world with limited obstetric facilities but where majority of deaths occur. Studies have shown that oral misoprostol is as effective as oxytocin in active management of third stage of labour. ${ }^{2}$

The present study is an attempt to evaluate the scope and feasibility of using rectal misoprostol in comparison with intramuscular methyl ergometrine and intramuscular carboprost, which are being used by many clinicians in our country for the active management of third stage of labour.

The aim of the study was to assess the efficacy and safety of Misoprostol 800ug per rectally in active management of third stage of labour.
The objectives of the study were to analyse the amount of blood loss during and duration of the third stage of labour and to compare the effectiveness of rectal misoprostol with intramuscular Methyl ergometrine and Carboprost.

\section{METHODS}

This prospective study was conducted in a single working unit of the Department of Obstetrics and Gynaecology, in a major tertiary care institute over a period of two years from September 2009 to July 2011. Permission for this study was obtained from the local ethical committee of the teaching hospital.

Two hundred women who delivered after 34 weeks of gestation with or without episiotomies in a tertiary care institute were enrolled.

After admission, the eligibility of the woman for enrolment in the study was assessed. A thorough obstetric examination for the duration of pregnancy, presentation, amount of liquor, foetal wellbeing was done. Per vaginal examination for dilatation, effacement of the cervix, presentation and assessment of pelvis was also done before enrolling the patient into the study, every woman was explained the type and nature of the study and informed consent was taken. Women in age group of 2035 years with singleton pregnancy with spontaneous onset of labour with gestational age > 34 weeks with vertex presentation were included in the study. Patients having medical disorders like Pregnancy induced hypertension, Cardiac disease, sensitivity to prostaglandins, and history of previous caesarean section were excluded from the study.

On admission, the age, the parity, gestational age in weeks, antenatal risk factor if any was noted. The Haemoglobin level of every woman was noted on admission.

Two hundred women were randomly divided by using randomization table into four groups of fifty each depending on the drug to be given at birth of the anterior shoulder for active management of third stage of labour.

A. Group A consisted of 50 women to be given800ugof Misoprostol per rectally.

B. Group B consisted of 50 women to be given $0.2 \mathrm{mg}$ of Methyl ergometrine intramuscularly.

C. Group C consisted of 50 women to be given $125 \mathrm{ug}$ of Carboprost (PGF2 $\alpha$ ) intramuscularly.

D. Group D consisted of 50 women not to be given any prophylactic oxytocic's (Control group).

All women were monitored in the first and second stage of labour and partogram was maintained. The mean duration of the first and second stage of labour, any medication or intervention required in the first and second stage, and any complications in the first and second stage were noted. The first, second and third stage 
of labour was managed and delivery was conducted as per unit protocol. Women who were enrolled but required emergency caesarean section were excluded from the study. Operative vaginal delivery was performed in indicated cases.

The drug was administered prophylactically at the birth of the anterior shoulder of the baby as per the group in which they were enrolled.

After delivery of the baby, placenta was delivered by controlled cord traction following evidence of signs of placental separation. Placenta was carefully examined for completeness and if there is any abnormality.

The duration of third stage of labour was calculated from the time of birth of the baby to the time of expulsion of the placenta. The amount of blood loss during third stage was noted. The blood loss was evaluated as follows. The blood and blood clots in the kidney tray were weighed. A plastic pouch was placed under the buttocks prior to the delivery. The blood lost was collected in this pouch. After the delivery of the placenta, the content of the pouch was transferred to the graduated jar. The blood volume was expressed in millilitres.

The blood soaked in linen and sponges was accounted in the following way:

- The soiled linen and sponges used were weighed.

- The weight $1 \mathrm{gm}$ equal to $1 \mathrm{ml}$.

- The known dry weight subtracted and the calculated volume added to that from the plastic pouch.

Any complication occurring during third stage of labour was noted. Repeat Haemoglobin levels were sent 24 hours after delivery. Routine post natal care was given to all women.

The women having significant bleeding after one dose were given an additional dose after 10-15 min depending upon the severity of blood loss. If the bleeding persisted after two additional doses, the woman was given another oxytocic drug included in the study.

In the control group, women were mainly managed by bimanual compression of the uterus. In cases where there was persistent bleeding, women were started oxytocin infusion.

In case of complications like retained placenta, cervical tear women were monitored and managed as per protocol. In case of occurrence of postpartum haemorrhage, operative intervention was planned.

The results of all four groups were compared with each other.

\section{Statistical analysis}

The Analysis of variance (ANOVA) was used to compare duration of third stage of labour and amount of blood loss and difference in haemoglobin between all four groups using SPSS 15.0 and Open Epi 2.3 epidemiological calculator (CDC approved).

\section{RESULTS}

Out of 200 women, maximum women (41\%) were in the age group of 21-25 years. 72 patients were primigravidas $(36 \%)$ and 128 were multigravidas $(64 \%)$. Maximum no of women were between 37-38 weeks of gestation i.e. 97 $(48.5 \%)$ which was followed by $39-40$ weeks i.e. 56 (28\%).

Table 1: Duration of third stage of labour.

\begin{tabular}{|c|c|c|c|c|c|}
\hline $\begin{array}{l}\text { Duration } \\
\text { (minutes) }\end{array}$ & $\begin{array}{l}\text { Group A } \\
\text { (Misoprostol) }\end{array}$ & $\begin{array}{l}\text { Group B } \\
\text { (Methyl ergometrine) }\end{array}$ & $\begin{array}{l}\text { Group C } \\
\text { (Carboprost) }\end{array}$ & $\begin{array}{l}\text { Group D } \\
\text { (Control) }\end{array}$ & $\%$ \\
\hline$<5$ & 20 & 12 & 12 & 11 & 27.5 \\
\hline $6-10$ & 17 & 26 & 24 & 26 & 46.5 \\
\hline $11-15$ & 10 & 10 & 14 & 10 & 22 \\
\hline$\geq 16$ & 3 & 2 & 0 & 3 & 4 \\
\hline Total & 50 & 50 & 50 & 50 & 100 \\
\hline
\end{tabular}

184 patients $(92 \%)$ underwent normal delivery whereas $16(8 \%)$ needed forceps or vacuum application. The indications of assisted delivery were mainly prolonged second stage of labour, maternal exhaustion, fetal compromise (meconium stained liquor or non-reassuring fetal heart rate). According to the drug given prophylactically, patients were divided into four groups for analysis.
The maximum no of women had their duration of third stage of labour between 6-10 minutes $(46.5 \%)$. This was followed by women who had their duration of third stage between $<5$ minutes $(27.5 \%)$. However, maximum no of women in whom duration of third stage of labour was less than 5 minutes belonged to the misoprostol group (Table 1). 
The average duration of the third stage of labour was shortest in Misoprostol group (8.88min) and highest in the control group (9.56min).

Table 2: Average duration of third stage of labour.

\begin{tabular}{|llll|}
\hline Groups & $\begin{array}{l}\text { Mean } \\
\text { duration of } \\
3^{\text {rd }} \text { stage of } \\
\text { labour(min) }\end{array}$ & SD & Significance \\
\hline Misoprostol & 8.88 & 5.00 & 1.00 \\
\hline $\begin{array}{l}\text { Methyl } \\
\text { ergometrine }\end{array}$ & 8.96 & 3.61 & 1.00 \\
\hline Carboprost & 8.90 & 3.59 & 1.00 \\
\hline Control & 9.56 & 4.63 & 1.00 \\
\hline
\end{tabular}

One way ANOVA $(\mathrm{p}=0.832)$

Table 3: Average blood loss.

\begin{tabular}{|c|c|c|c|}
\hline Drug & $\begin{array}{l}\text { Mean blood } \\
\text { loss }(\mathrm{ml})\end{array}$ & SD & $P$ value \\
\hline Misoprostol & 124.40 & 34.709 & \multirow{5}{*}{$<0.001$} \\
\hline $\begin{array}{l}\text { Methyl } \\
\text { ergometrine }\end{array}$ & 152.20 & 49.293 & \\
\hline Carboprost & 153.80 & 43.467 & \\
\hline Control & 167.40 & 52.946 & \\
\hline Total & 149.45 & 47.913 & \\
\hline
\end{tabular}

One way ANOVA $(\mathrm{p}=0.000001)$

There was no statistically significant difference in average duration of third stage of labour between groups as determined by one-way ANOVA $(\mathrm{F}=0.291, \mathrm{p}=$ 0.832). Bonferroni A post-hoc test revealed that the duration of $3^{\text {rd }}$ stage of labour was not statistically significant among any of the groups (Table 2).

There was a statistically significant difference in average blood loss between groups as determined by one-way ANOVA ( $\mathrm{F}=7.815, \mathrm{p}=0.000001)$. Bonferroni A posthoc test revealed that reduction in the amount of blood loss was significantly significant with Misoprostol as compared to Ergometrine $(\mathrm{p}=0.016)$, Carboprost $(\mathrm{p}=0.009)$, and control $(\mathrm{p}=0.00001)$. It was statistically significant in comparison of Carboprost with control $(\mathrm{p}=0.026)$. Similarly reduction in blood loss by Ergometrine was not statistically significant as compared to the control $(\mathrm{p}=0.05)$ (Table 3$)$.

In Misoprostol group, maximum blood loss occurred when duration was 6-10 min and minimum blood loss occurred when the duration was more than 16 minutes. In Ergometrine group, maximum blood loss occurred when the duration was more than 16 minutes while minimum blood loss occurred when the duration was 6-10 minutes. In Carboprost group, maximum blood loss occurred when the duration was less than 5 minutes and minimum blood loss occurred when the duration was between 6-10 minutes. In the control group, maximum blood loss occurred when the duration was between 11-15 minutes and minimum blood loss occurred when the duration was between 6-10 minutes. However in 8 women, the duration of third stage was more than 16 minutes but the average blood loss was less. This was mainly because as the placenta took longer time to separate, blood loss was decreased due to compression of the placenta against the uterine wall (Table 4).

Table 4: Average blood loss in relation to duration of third stage of labour.

\begin{tabular}{|lllll|}
\hline $\begin{array}{l}\text { Duration of } 3^{\text {rd }} \\
\text { stage of labor (min) }\end{array}$ & Group A (Misoprostol) & Group B (Methyl ergometrine) & Group C (Carboprost) & Group D(Control) \\
\hline$<5$ & 117.5 & 161.6 & 163.3 & 170 \\
\hline $6-10$ & 141.1 & 142.3 & 150 & 165 \\
\hline $11-15$ & 117 & 159 & 152.1 & 175 \\
\hline$\geq 16$ & 100 & 190 & - & 153.3 \\
\hline
\end{tabular}

The difference in pre and post-delivery Haemoglobin is significant in all four groups by applying the one way ANOVA test. However, the decrease in Haemoglobin is the least in the Misoprostol group as compared to the other groups.

There was a statistically significant difference between groups as determined by one-way ANOVA ( $\mathrm{F}=6.442$, $\mathrm{p}$ $=0.000001)$. Bonferroni $\mathrm{A}$ post-hoc test revealed that difference in the pre and post-delivery haemoglobin was significantly significant with Misoprostol as compared to Methyl Ergometrine $(p=0.048)$, Carboprost $(p=0.0001)$, and control $(\mathrm{p}=0.006)$. It was not statistically significant in comparison of Carboprost with Methyl Ergometrine $(\mathrm{p}=0.868)$ and control $(\mathrm{p}=1.00)$. Similarly difference in haemoglobin by Methyl Ergometrine was not statistically significant as compared to the control $(\mathrm{p}=1.00)$ (Table 5).

Seven patients required additional doses for control of bleeding. Four patients were of Carboprost group, two of Methyl ergometrine group and one from the Misoprostol group. Five patients from the control group required an oxytocic to be given of which three were given oxytocin infusion and two were given intramuscular methyl ergometrine. 
Table 5: Comparison of difference in hemoglobin pre and post-delivery.

\begin{tabular}{|lllll|}
\hline Drug & $\begin{array}{l}\text { Pre delivery } \\
\text { Hemoglobin } \\
\text { (Mean) }\end{array}$ & $\begin{array}{l}\text { Post delivery } \\
\text { Hemoglobin } \\
\text { (Mean) }\end{array}$ & $\begin{array}{l}\text { Difference in Hemoglobin } \\
\text { (Mean } \pm \text { SD) }\end{array}$ & p value \\
\hline Misoprostol & 10.98 & 10.49 & $0.49 \pm 0.05$ & $<0.001$ \\
\hline Ergometrine & 10.66 & 9.90 & $0.76 \pm 0.02$ & \\
\hline Carboprost & 10.71 & 9.81 & $0.9 \pm 0.12$ & \\
\hline Control & 10.88 & 10.07 & $0.81 \pm 0.02$ & \\
\hline
\end{tabular}

One way ANOVA $(\mathrm{p}=0.000001)$

Table 6: Side effects of drugs.

\begin{tabular}{|ll|ll|l|}
\hline Side effects & Group A (Misoprostol) & Group B (Methyl ergometrine) & Group C(Carboprost) & Total \\
\hline Pain in abdomen & 1 & 9 & 1 & 11 \\
\hline Shivering & 10 & 0 & 0 & 10 \\
\hline Vomiting & 0 & 1 & 8 & 9 \\
\hline Diarrhoea & 0 & 0 & 7 & 7 \\
\hline Nausea & 6 & 1 & 0 & 7 \\
\hline Pyrexia & 6 & 0 & 0 & 6 \\
\hline
\end{tabular}

All groups had side effects. Pain in abdomen was treated with analgesics. Shivering was treated with anti pyretics. Women with vomiting were treated with anti-emetics. (Table 6).

Three women had cervical tear which were sutured. One patient from the Methyl Ergometrine group had retained placenta which was manually removed under general anaesthesia. Rest of the women had an uneventful course. Postpartum haemorrhage was not seen in any women. No women required blood transfusion.

\section{DISCUSSION}

Postpartum hemorrhage (PPH) is the leading cause of maternal mortality. Although maternal mortality rates have declined greatly in the developed world, PPH remains a leading cause of maternal mortality elsewhere. In the developing world, several countries have maternal mortality rates in excess of 100 women per 100,000 live births, and World Health Organization statistics suggest that $25 \%$ of maternal deaths are due to $\mathrm{PPH}$, accounting for more than 100,000 maternal deaths per year. The most recent Practice Bulletin from the American College of Obstetricians and Gynecologists places the estimate at 140,000 maternal deaths per year or 1 woman every 4 minutes. ${ }^{3}$

According to the WHO Reproductive Health Library (March 2009) $^{4}$, active management of third stage of labour was associated with less blood loss, lower risk of blood transfusion, reduced duration of the third stage of labour and reduced risk of maternal anemia as compared to expectant management. However, active management is associated with an increased risk of nausea, vomiting and raised blood pressure.
The underlying principle in active management is to excite powerful uterine contractions following birth of the anterior shoulder by parenteral oxytocic which facilitates not only early separation of the placenta but also produces effective uterine contractions following separation.

Active management of the third stage of labour includes administration of a prophylactic uterotonic at or after delivery of the baby, early cord clamping and cutting and controlled cord traction to deliver the placenta ${ }^{5}$. Active management should be practiced by all skilled attendants at every birth to prevent postpartum haemorrhage. It is however, contraindicated in high risk pregnancies like those with PIH, multiple gestation, cardiac and renal patients etc.

The incidence of postpartum haemorrhage varies from 2$11 \%$. Postpartum haemorrhage complicates approximately $4 \%$ of deliveries in most large obstetric services. The incidence is $0.5 \%$ amongst hospital deliveries and postpartum haemorrhage causes 10-16\% maternal deaths in India. ${ }^{6}$

Pritchard and associates (1962) used precise methods and found that approximately 5 percent of women delivering vaginally lost more than $1000 \mathrm{~mL}$ of blood. They also reported that estimated blood loss is commonly only approximately half the actual loss. Because of this, estimated blood loss in excess of $500 \mathrm{~mL}$ should call attention to mothers who are bleeding excessively. ${ }^{7}$

In all four groups majority of the women belong to the age group 21-25 years ie.82 of which distribution is 21 (Misoprostol group), 25 (Ergometrine group), 24 (Carboprost group) and 12 (Control group). In a similar 
study by Frederic et al the mean age in all groups was 29 yrs.

There was no statistically significant difference between the duration of third stage of labour in all the groups as determined by the One way ANOVA test $(\mathrm{F}=0.291, \mathrm{p}=$ .832).In a study by Joshi $\mathrm{V}$ when misoprostol was compared to methyl ergometrine, there was reduction in mean length of third stage from 4.18 mins in methyl ergometrine group to 3.98 mins misoprostol group. ${ }^{8}$

There was a statistically significant difference between the average blood loss in all groups as determined by One way ANOVA $(\mathrm{F}=7.815, \mathrm{p}=0.000001)$. It showed that reduction in blood loss was significantly significant in Misoprostol group as compared to Ergometrine $(\mathrm{p}=0.016), \quad$ Carboprost $\quad(\mathrm{p}=0.009), \quad$ and control $(\mathrm{p}=0.00001)$. It was statistically significant in comparison of Carboprost with control $(\mathrm{p}=0.026)$. Similarly reduction in blood loss by Ergometrine was statistically significant as compared to the control $(\mathrm{p}=0.05)$.

This was in contrast with the study conducted by Grestenfeld $^{9}$ and Wing on a total of 325 women who were randomised to receive two $200 \mu \mathrm{g}$ Misoprostol tablets rectally (study medication) plus $2 \mathrm{ml}$ saline in Ringers lactate IV Or two lactose tablets rectally plus 20units oxytocin in Ringers lactate IV (control medication). By estimation $21 \%$ of subjects and $15 \%$ of controls had postpartum haemorrhage $(\mathrm{p}=17)$, by using measured blood loss $46 \%$ study subjects and $38 \%$ control subjects had PPH $(\mathrm{p}=17)$ for $23 \%$ Misoprostol subjects and $11 \%$ oxytocin subjects at least one additional agent was required to control bleeding $(\mathrm{p}=0.04)$.It was concluded rectal Misoprostol $(400 \mu \mathrm{g})$ was no more effective than IV oxytocin in preventing postpartum haemorrhage.

The results of our study were comparable to the study conducted by Prata N who compared the current practices used in active management in third stage of labour with $600 u g$ of oral misoprostol. ${ }^{10} \mathrm{He}$ concluded that in situations where oxytocin and or ergometrine are not consistently and appropriately used during third stage of labor, misoprostol should be considered for inclusion in the AMTSL protocol. He also concluded that the mean blood loss was less in the misoprostol group.

Puroshottum BJ compared intramuscular PGF2 $\alpha$ with intravenous methyl ergometrine during active management of third stage of labour in high risk patients prone to develop atonic postpartum haemorrhage and concluded that prophylactic PGF $2 \alpha$ is a better alternative as compared to intravenous ergometrine.

In our study the difference in Haemoglobin was significant in all groups which was determined by applying the one way ANOVA test ( $\mathrm{f}=351.78, \mathrm{p}=$ $<0.001)$. In a study conducted by Walley RL et al where he compared misoprostol with oxytocin in active management of third stage of labour, there was no significant difference in the haemoglobin before and after delivery. ${ }^{12}$
In our study, side effects were mainly seen in the methyl ergometrine group. Twenty percent of patients in the Misoprostol group had shivering as compared to none in the other two groups. Shivering was however self-limited and subsided within 10-15 minutes in all cases.

This finding was comparable with the WHO multicentre trial of Misoprostol in the management of third stage of labour, where they concluded that oral Misoprostol was associated with significantly high incidence of side effects like shivering and rise in body temperature and hence oxytocin is preferred to $600 \mathrm{mg}$ of oral Misoprostol in management of 3rd stage of labour in hospital settings, but still Misoprostol has been suggested for the management of third stage of labour in developing countries, because it has strong uterotonic effects, can be given orally, inexpensive and does not need refrigeration. $^{13}$

Amant $\mathrm{F}$ in their double blind study with methyl ergometrine and PGE1, concluded that although protection from postpartum haemorrhage using parenteral methyl ergometrine and oral Misoprostol is nearly equal; Misoprostol is associated with more side effects. But side effects of Misoprostol were self-limiting. ${ }^{14}$

Hofmeyer GJ and Gulmezoglu stated that Misoprostol is affordable, easily stored at room temperature and possess a shelf life of several years. ${ }^{15}$ Clinically insignificant hypertensive effects of a high oral dose of Misoprostol have been documented, a property which can be an advantage over the ergot containing oxytocic's which cause rise in blood pressure. An alternative approach is the administration of Misoprostol rectally. If rectal Misoprostol is confirmed in large studies to be effective in reducing postpartum blood loss, the low rate of side effects may be an important advantage of this route of administration.

Mansouri HA, Alsahly $\mathrm{N}^{16}$ compared rectal versus oral misoprostol 600ug in active management of third stage of labour in 658 patients. He found that oral misoprostol was associated with significantly more blood loss than rectal. Shivering and pyrexia were seen in more patients among the oral misoprostol group. They concluded that rectal misoprostol is effective in the management of third stage of labor, and with significant decrease in side effects.

Thus, per rectal misoprostol is equal or better as compared to injection methyl ergometrine or carboprost and can prove to be a better alternative because of the several advantages it offers which are as follows:

1. It has ease of administration as compared to both ergometrine and carboprost which need to be administered parenterally.

2. It requires no storage conditions and has a shelf life of several years. Both ergometrine and carboprost need to be stored at $2-8^{\circ} \mathrm{C}$ which is not feasible in many centres especially in developing country like ours. 
3. Misoprostol does not raise blood pressure in doses upto $800 \mathrm{mcg}$.

4. It is cheap and readily available.

In a developing country like India, where the vast majority of births (often more than 80\%) take place at home, very often attended by family members or by trained birth attendants, the health system is so weak that there is no hope of providing emergency obstetric care. In these conditions, the use of misoprostol for the management of third stage of labour, with its ease of administration, shelf life of several years at room temperature and low cost can be a long term solution in decreasing the maternal morbidity and mortality.

\section{CONCLUSION}

There was a statistically significant difference in the amount of blood loss in the misoprostol group as compared to the other three groups. There was also no significant difference in the duration of third stage of labour in all four groups. Our study also showed that the side effects were seen mainly in the misoprostol group but were not significant and were easily reversible. We observed that Misoprostol 800ug per rectally as compared to intramuscular methyl ergometrine and carboprost is an effective alternative in active management of third stage of labour.

The rectal route of misoprostol administration is well tolerated, and the usual side effects of shivering and increased temperature were noted only infrequently. It is more feasible than the other two due to ease of administration and storage conditions. Thus, misoprostol is an effective uterotonic and provides a simple therapeutic option for health care providers in developing nations to use in the battle against obstetric haemorrhage.

Funding: Not required

Conflict of interest: None declared

Ethical approval: The study was approved by the Institutional Ethics Committee

\section{REFERENCES}

1. Prendiville WJ, Elbourne D, McDonald S. Active versus expectant management in the third stage of labour. Cochrane Database Syst Rev. 2000(3).

2. Afolabi EO, Kuti O. Oral misoprostol versus intramuscular oxytocin in the active management of third stage of labour Singapore Med J. 2010;51(3):207-11.

3. American College of Obstetricians and Gynecologists. ACOG Practice Bulletin: Clinical Management Guidelines for ObstetricianGynecologists Number 76, October 2006: postpartum hemorrhage. Obstet Gynecol. 2006;108(4):1039-47.
4. Abalos E. Active versus expectant management of the third stage of labour: RHL commentary (last revised: 2 March 2009). The WHO Reproductive Health Library; Geneva: World Health Organization.

5. Nagaria T, Sahu B. 400ug oral Misoprostol versus $0.2 \mathrm{mg}$ intravenous Methyl ergometrine for the active management of the third stage of labour.J Obstet Gynacol India. 2009:59:228-34.

6. Cunningham FG, Leveno KJ, Bloom SL, Hauth JC. Obstetrical Hemorrhage, Williams Obstetrics , 23nd Edn. Philadelphia. McGraw Hill; 2010; pp 757-803.

7. Pritchard JA, Baldwin RM, Dickey JC, Wiggins KM. Blood volume changes in pregnancy and puerperium, II: red blood cell loss and changes in apparent blood volume during and following vaginal delivery, cesarean section, and cesarean section plus total hysterectomy. American Journal of Obstetrics and Gynecology. 1962;84:1271-82.

8. Joshi V, Sapre S, Jaiswal N, Olyai R.Comaparative study between per rectal misoprostol and IM methergin for prophylaxis of PPH. Obstet Gynecol Today. 2006;XI(3):160-2.

9. Gerstenfeld TS and Wing AD. Rectal misoprostal verses intravenous oxytocic for the prevention of post partum haemorrhage after vaginal delivery. (Am J. Obstet Gynecol. 2001;185:878-82.

10. Prata N, Hamza S, Gypson R. Misoprostol and active management of the third stage of labor Int.J Obstet Gynaecol. 2006:94:149-55.

11. Purushottam BJ, Patil R. Prophylactic intramuscular PGF2 $\alpha$ versus intravenous methyl ergometrine for prevention of atonic PPH in high risk women $\mathbf{J}$ Obstet Gynaecol India. 2008:58:417-20.

12. Walley RL, Wilson J, Mathews K. A double blind placebo controlled trial of Misoprostol and Oxytocin in the management of third stage of labor Br J Obstet Gynaecol. 2000;107:1111-5.

13. WHO Multi Center randomized trial in the management of the third stage of labour. The Lancet. 2001;358:689-95.

14. Amant F, Spitz B, Corremans A. Misoprostol compared with methyle ergometerine for the prevention of PPH a double blind randomized trial. British Journal of Obstet and Gynecol. 1999;106:1066-70.

15. Hofmeyr GJ Gulmezoglu A. Metinnew developments in the management of post partum haemorrhage. In John Bonnar, Editor, Recent advances in Obstetrics and Gynecol 21st Edn. Ne Delhi; Harcourt Publishers Limited; 2001 pp 55-66.

16. Mansouri HA, Alsahly N, Rectal versus oral misoprostol for active management of third stage of labor : a randomized controlled trial, Arch Gynecol Obstet , 2011;283(5):935-9.

Cite this article as: Supe PA, Kore SJ, Nandanwar YS. A comparative study of efficacy of misoprostol with methyl ergometrine and carboprost in active management of third stage of labour. Int J Reprod Contracept Obstet Gynecol 2016;5:1525-31. 